\title{
Tidal triggering evidence of intermediate depth earthquakes in the Vrancea zone (Romania)
}

\author{
N. Cadicheanu ${ }^{1}$, M. van Ruymbeke' ${ }^{2}$ and P. $\mathbf{Z h u}^{2}$ \\ ${ }^{1}$ Institute of Geodynamics of the Romanian Academy, 19-21, Jean-Louis Calderon St., Bucharest-37, 020032, Romania \\ ${ }^{2}$ Royal Observatory of Belgium, 3, Avenue Circulaire, 1180- Brussels, Belgium
}

Received: 15 June 2007 - Revised: 19 June 2007 - Accepted: 19 June 2007 - Published: 30 November 2007

\begin{abstract}
Tidal triggering evidence of intermediate earthquakes in the Vrancea region (Romania) is investigated. The Vrancea seismic zone is located in the bend region of the South-Eastern Carpathians $\left(45^{\circ}-46^{\circ} \mathrm{N}, 25.5^{\circ}-27.5^{\circ} \mathrm{E}\right)$ and is known as one of the most active seismic zones in Europe. We selected earthquakes occurred between 1981 and 2005 from the RomPlus catalog provided by the Institute of Earth Physics of Bucharest with $M w \geq 2.5$ and focal depths between 60 and $300 \mathrm{Km}$.

We assigned a tidal component phase angle for each event which is computed from the earthquake occurrence time. Then the phase angle distribution was obtained by stacking every angle value in a 360 degree coordinate. Main lunar and solar semidiurnal tidal components $M 2$ and $S 2$ are considered. The phase angle distributions are tested by Permutation test which are introduced for the first time to a tidal triggering study. We compared results with classical Schuster's test. Both tests produce one value, $p_{p}$ for Permutation test and $p_{s}$ for Schuster's test, which represent the significance level for rejecting the null hypothesis that earthquakes occur randomly irrespective of tidal activities $M 2$ and $S 2$ phase distribution are random for the complete data set. However, when we set up a one year window and slide it by $30 \mathrm{~d}$ step, significant correlations were found in some windows. As a result of the sliding window, data set systematic temporal patterns related to the decrease of the $p_{p}$ and $p_{s}$ values seem to precede the occurrence of larger earthquakes.
\end{abstract}

Correspondence to: $\mathrm{N}$. Cadicheanu

(cadichian_nicoleta@yahoo.fr)

\section{Introduction}

Although the amplitude of the tidal stress change is two or three orders smaller than the stress drop of earthquakes, the tidal stress rate could be comparable to the tectonic stress rate and generally larger than this. It is reasonable to expect tidal triggering of an earthquake when the stress in the focal area is near the critical level (Tanaka et al., 2006).

At the intermediate seismic focal depth levels $(60 \mathrm{~km}<$ focal depth $<300 \mathrm{~km})$, the gravitational force is the main outside force which could affect the dynamic process of the inner Earth. Its systematic variations are controlled by the lunar-solar attraction forces on each terrestrial point. It can be calculated through the precisely defined periods of the earth tides that vary from few hours (e.g. diurnal and semi-diurnal waves) to years (Melchior, 1978). Earth tides are deeply modulated signals which depend on the Sun and Moon's orbital parameters. For the main position on orbits, declination, ellipticity, and positions of the nodes, each is related to the absolute sidereal reference. Local and regional heterogeneities lead to a different response from one zone to another in accordance with the geological and tectonic background and it could also be influenced by the regional characteristics of the mantle-crust interface with a viscous coupling mechanism.

In summary, the response of a seismic zone to tidal periodicities depends on its specific geology, tectonic history and stress accumulation mechanisms in this region. The tidal modulation tendencies in seismic activity could help explain some aspects of the physical mechanism of rupture forming. A remarkable number of studies have been devoted to the possibility of triggering of earthquakes by earth tides. Most have reported negative conclusions about the correlation between the earth tide and earthquake occurrence (Schuster, 1897; Knopoff, 1964; Simpson, 1967; Shudde and Barr, 1977; Heaton, 1982; Curchin and Pennington, 1987; Rydelek et al., 1992; Vidale et al., 1998). However, many

Published by Copernicus Publications on behalf of the European Geosciences Union. 


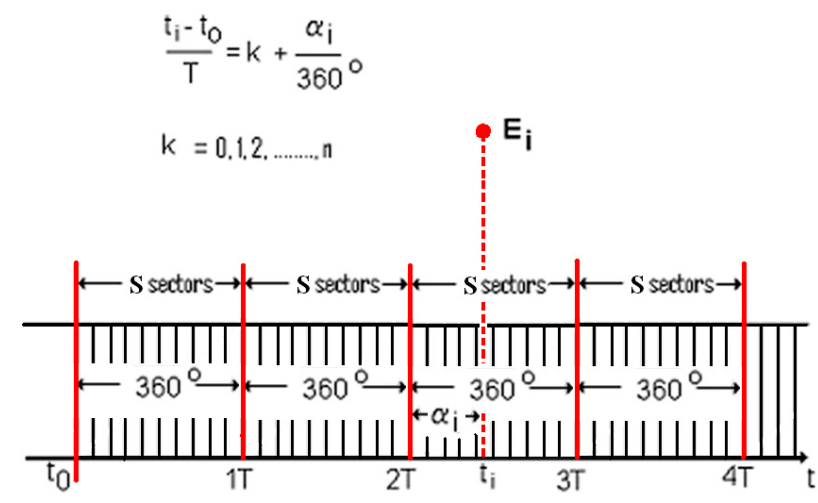

Fig. 1. Time series partition into selected time period $T$. An event $E_{i}$ occurring at time $t_{i}$ will defined by an angle $\alpha_{i}$.

Table 1. Earth tide components and their periodicities.

\begin{tabular}{lcccc}
\hline $\begin{array}{l}\text { Earth tide } \\
\text { component }\end{array}$ & $\begin{array}{c}\text { Doodson } \\
\text { argument }\end{array}$ & $\begin{array}{c}\text { Angular } \\
\text { frequency }(\% / \mathrm{h})\end{array}$ & $\begin{array}{c}\text { Periodicity } \\
(\mathrm{h})\end{array}$ & $\begin{array}{c}\text { Amplitude } \\
(\text { microgal })\end{array}$ \\
\hline$S 2$ & 273.555 & 30.000000 & 12.000000 & 42.286 \\
$M 2$ & 255.555 & 28.984104 & 12.421000 & 90.812 \\
\hline
\end{tabular}

recent papers have indicated positive correlations (Enescu and Enescu, 1999; Stavinschi and Souchay, 2003; Stroup, 2007; Tsuruoka et al., 1995; Tolstoy et al., 2002; Tanaka et al., 2002, 2006; Zugravescu et al., 1985, Zugravescu et al., 1989; Wilcock, 2001). Based on the recent positive studies by Tanaka et al. $(2002,2006)$ we reinvestigated the role of the earth tides on triggering earthquakes in Vrancea area , one of the most active seismic zones in Europe (Knapp et al., 2005). In this paper, we statistically test the significance level of the effect of the two semidiurnal components on intermediate depth earthquakes in Vrancea (Table 1).

We applied the same Schuster's statistical test which has been widely used in tidal triggering studies (Tanaka et al., 2002, 2006). A different approach based on the Permutation test was also introduced. It could extend statistical studies where Schuster's test is not adequate. Validation of the conclusions becomes more robust if both tests show similarities.

\section{Method of analysis}

A stacking analysis method named HiCum (Histogram $\mathrm{Cu}$ mulating) (van Ruymbeke et al., 2003, 2007, Cadicheanu et al., 2006), is applied to compute the tidal potential phase angles of earthquakes. First, time based events are divided into a series of intervals with a priori selected constant periods $\mathrm{T}$ which could be any tidal component. This time period $\mathrm{T}$ is represented by an interval $1^{\circ}-360^{\circ}$. Then the time base for each period is normalized as shown in Fig. 1. For

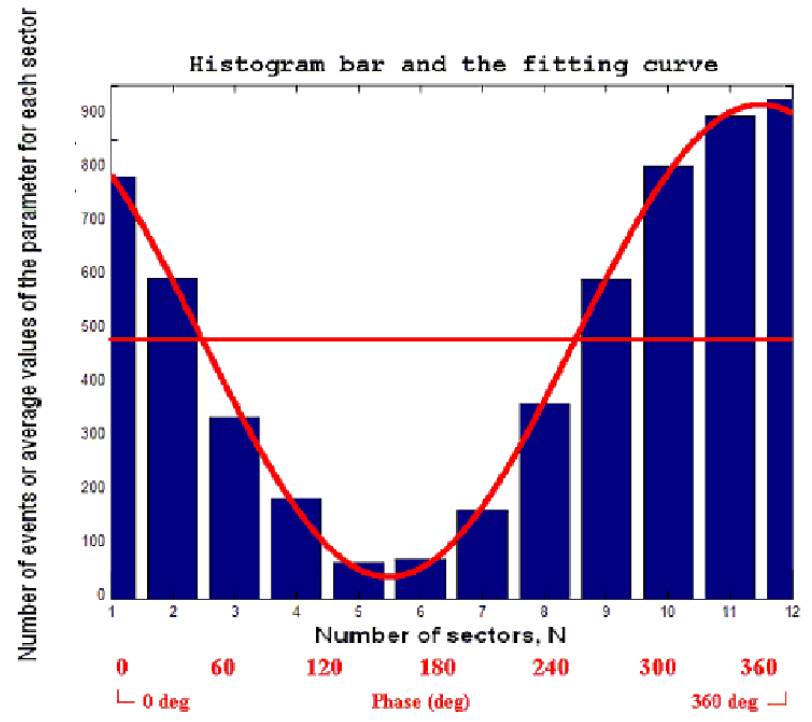

Fig. 2. A histogram bar model with 12 sectors, representing the distribution of the seismic activity or the average value of the parameter for each sector and the corresponding sinusoidal fitting curve.

each component, the original phase is fixed from astronomical data. The event $E_{i}$ occurred at time $t_{i}$ was characterized by the phase $\alpha_{i}$. For the selected tidal period $T$ a histogram of events is established as a function of the $\alpha_{i}$. We divide histogram into $S$ sectors with length equal to $360^{\circ} / S$. The value of $S$ is selected when a significant number of events in each sector could be obtained.

We modelled the interactions of tidal components and earthquake with a cosine function adjusted to the histogram. The amplitude and phase of the cosine show the links, in terms of modulation, between the stacked events and the chosen tidal components (Fig. 2). Two main tidal components were selected for this research: the solar semidiurnal wave $S 2$ and the lunar semidiurnal wave $M 2$.

\section{Statistical tests}

\subsection{Schuster's test}

To begin, we statistically investigate the correlation between the tidal components and earthquake occurrences using Schuster's test. This test is a classical approach, which has been applied in past (Heaton, 1975, 1982; Tsuruoka et al., 1995; Tanaka et al, 2002, 2006).

In Schuster's test, each earthquake is represented by a unit length vector in the direction defined by its tidal phase angle $\alpha_{i}$ which was introduced in the Fig. 1 .

The vectorial sum $\boldsymbol{D}$ is defined as:

$\boldsymbol{D}^{2}=\left(\sum_{i=1}^{N} \cos \alpha_{i}\right)^{2}+\left(\sum_{i=1}^{N} \sin \alpha_{i}\right)^{2}$, 


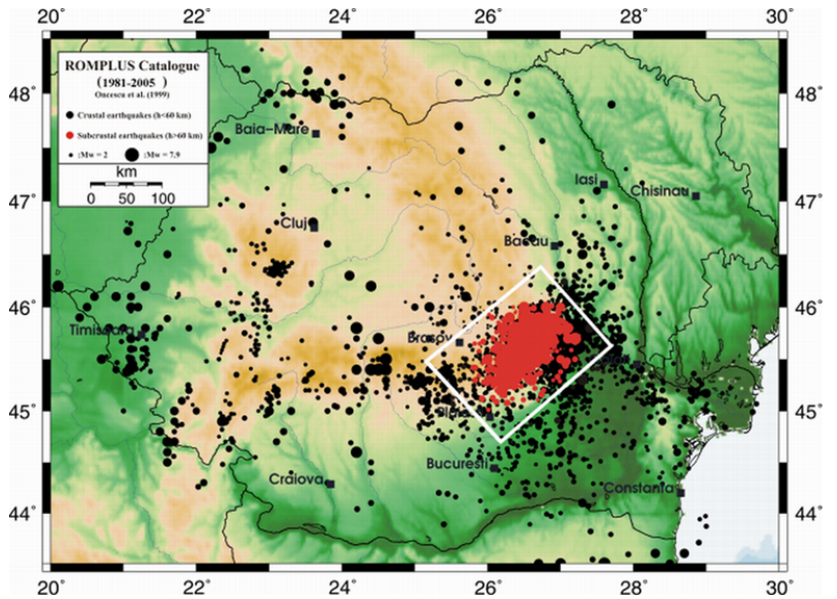

Fig. 3. The Vrancea earthquakes epicentres distribution (19812005) from RomPlus Catalog provided by Institute of the Earth Physics of Bucharest.

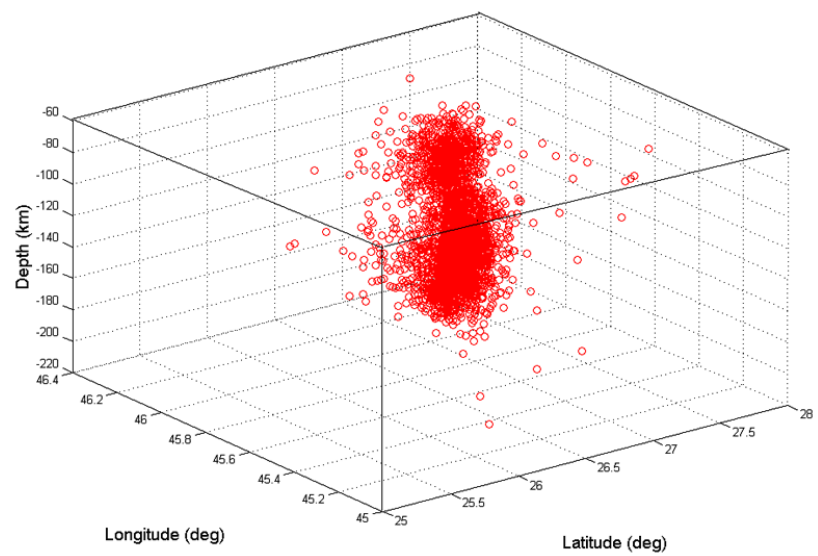

Fig. 4. Vrancea intermediate-depth seismic activity from 1981 to 2005 (a 3-D view of the hypocenter distribution).

where $N$ is the number of earthquakes. When the $\alpha_{i}$ is distributed randomly, the probability that the length of a vectorial sum is equal to or larger than $\boldsymbol{D}$ is given by Eq. (2):

$p_{s}=\exp \left(-\frac{\boldsymbol{D}^{2}}{N}\right)$

Thus, $p_{s}<5 \%$ represents the significance level at which the null hypothesis that the earthquakes occurred randomly with respect to the tidal phase is rejected.

To avoid the risk of spurious conclusions, which Schuster's test could induce, we must confirm the conclusions' robustness by a different approach. Thus, we introduce another statistical test.
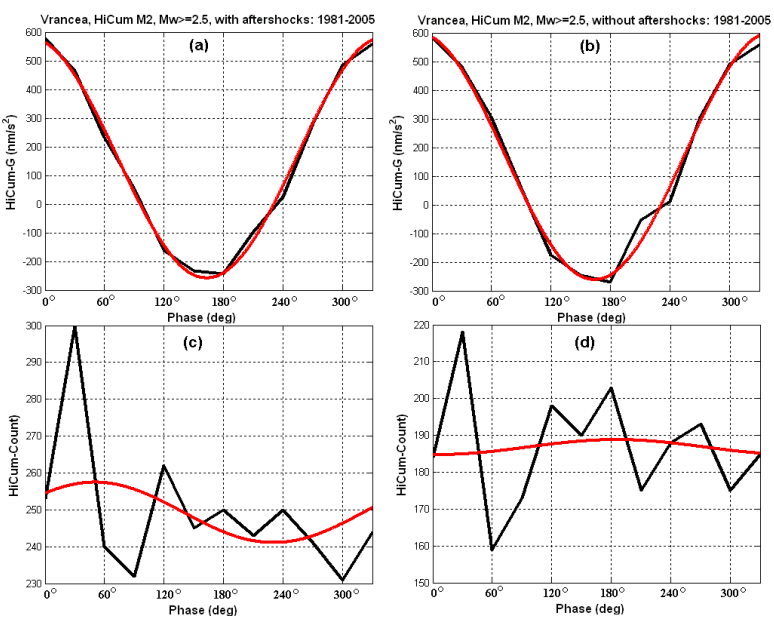

Fig. 5. Gravity theoretical values, (a) and (b), and the number of earthquakes distributions, (c) and (d), as a function of $M 2$ phase angle (black curves). The presence of aftershocks is tacked in account only in (a) and (c) cases. The fitting curves corresponding to each distribution are in red colour.
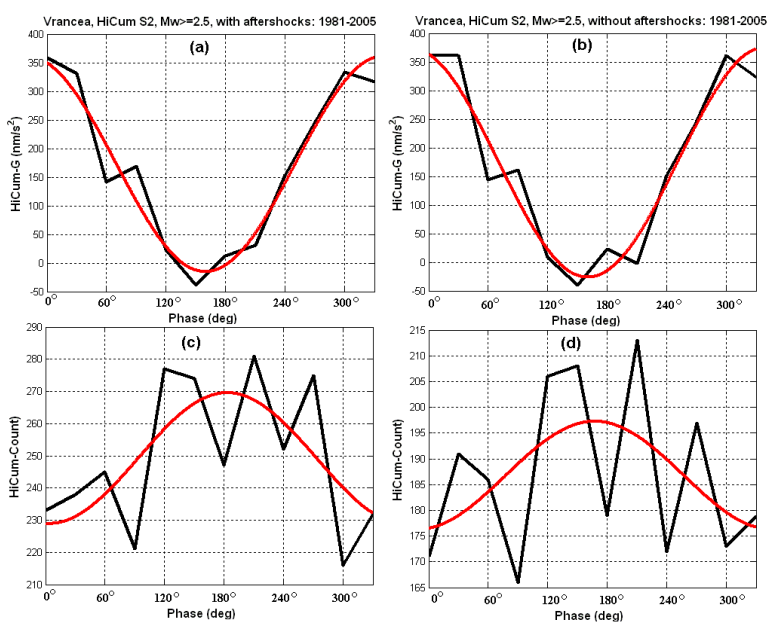

Fig. 6. Gravity theoretical values, (a) and (b), and the number of earthquakes distributions, (c) and (d), as a function of $S 2$ phase angle (black curves). The presence of aftershocks is tacked in account only in (a) and (c) cases. The fitting curves corresponding to each distribution are in red colour.

\subsection{Permutation tests}

We choose the permutation test which is well-known among biologists and geneticists because it is always free to choose the statistic which best discriminates between hypothesis and alternative. Permutation tests also allow for calculating the probability $\left(p_{p}\right)$ of the significance level to reject the null hypothesis in which the distribution is random.

It is also called a randomization test, re-randomization test, or an exact test; it is one type of statistical significance test in which a reference distribution is obtained by 


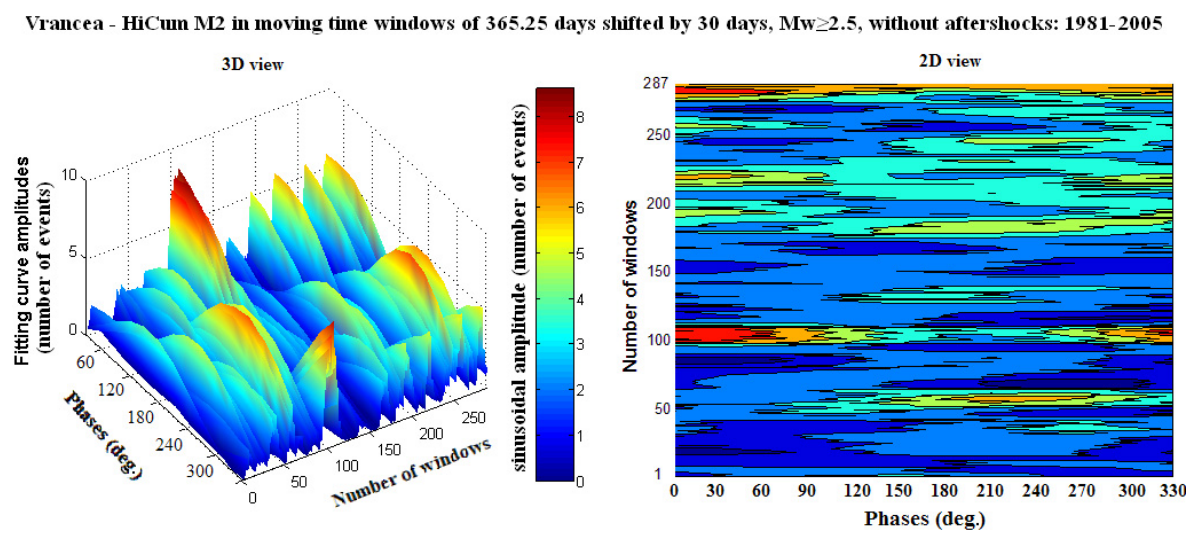

Fig. 7. The 3-D distribution of the HiCum fitting curves amplitudes expressed as the number of seismic events, and their corresponding 2-D view. For the HiCum analysis the $M 2$ wave period in sliding windows of one year, shifted by 30 days.

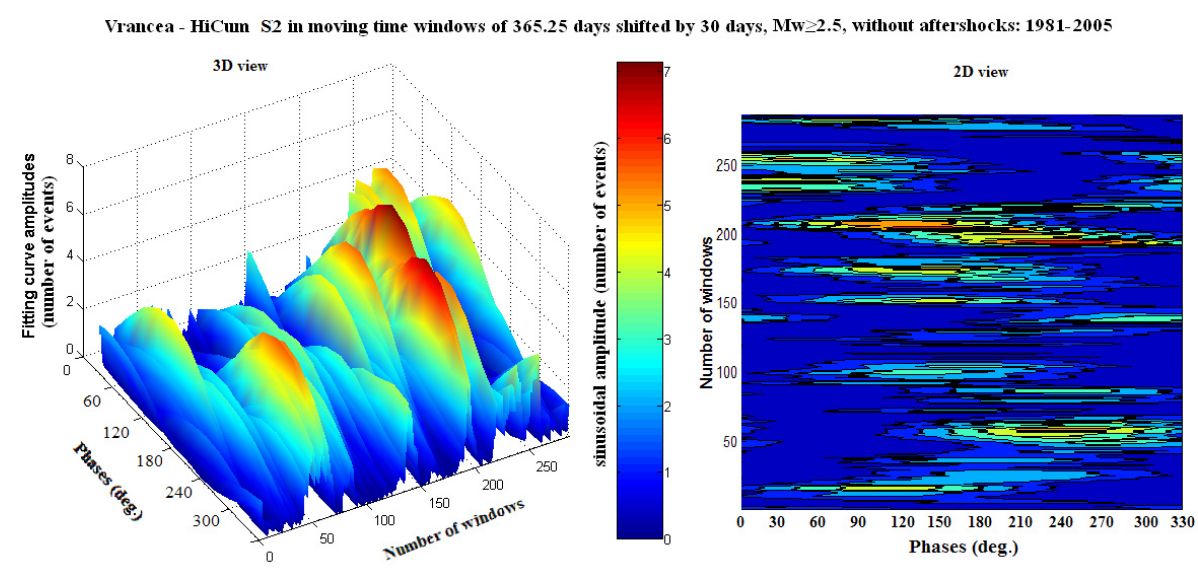

Fig. 8. The 3-D distribution of the HiCum fitting curves amplitudes expressed as the number of seismic events, and their corresponding 2-D view. For the HiCum analysis the $M 2$ wave period was used in sliding windows of one year, shifted by 30 days.

calculating all possible values by rearranging the labels on the observed data points.

In other words, the method is allocated to subjects in an experimental design that is mirrored in the analysis of that design. If the labels are exchangeable under the null hypothesis, then the resulting tests yield the exact significance levels. Then confidence intervals can be derived from the tests. The theory has evolved from the work of R. A. Fisher and E. J. G. Pitman (R. A. Fisher, 1935; E. J. G. Pitman, 1938). Permutation distribution is given by Eq. (3):

$p_{p}=\left(\sum_{l=0}^{m} A_{l}\right) / r$

Amplitude $A_{0}$ was obtained by a co-sinusoidal function which was fit to the distribution of HiCum stacking results after we produce $r$ random permutations distributions. We apply the HiCum on each permutation distribution and select only those that are significant according to amplitudes $A_{i}>A_{0}(i=0,1,2 \ldots m$ where $m \leq r)$.
If $p_{p}<5 \%$, it represents the significance level at which reject the null hypothesis, i.e. that the earthquakes occur randomly with respect to the tidal phase angle.

Both tests are applied on the entire earthquake catalogue and on the one year windowed data (sliding by one month) from 1981 to 2005. The $p_{s}$ and $p_{p}$-values are evaluated and compared.

\section{Vrancea seismic zone}

Earthquakes used in this study were selected from the RomPlus catalogue provided by the National Institute of Earth Physics, Bucharest. It contains nearly 3000 intermediate-depth earthquakes $(M w \geq 2.5)$ since 1981 to 2005 (Oncescu et al., 1999) (Fig. 3).

All epicentres are mainly located in a very narrow zone in the South-Eastern Carpathians $\left(45^{\circ}-46^{\circ} \mathrm{N}, 25.5^{\circ}-27.5^{\circ} \mathrm{E}\right)$ at the intra-continental collision between the East European plate, Intra-alpine, and Moesian micro-plates (Ardeleanu, 


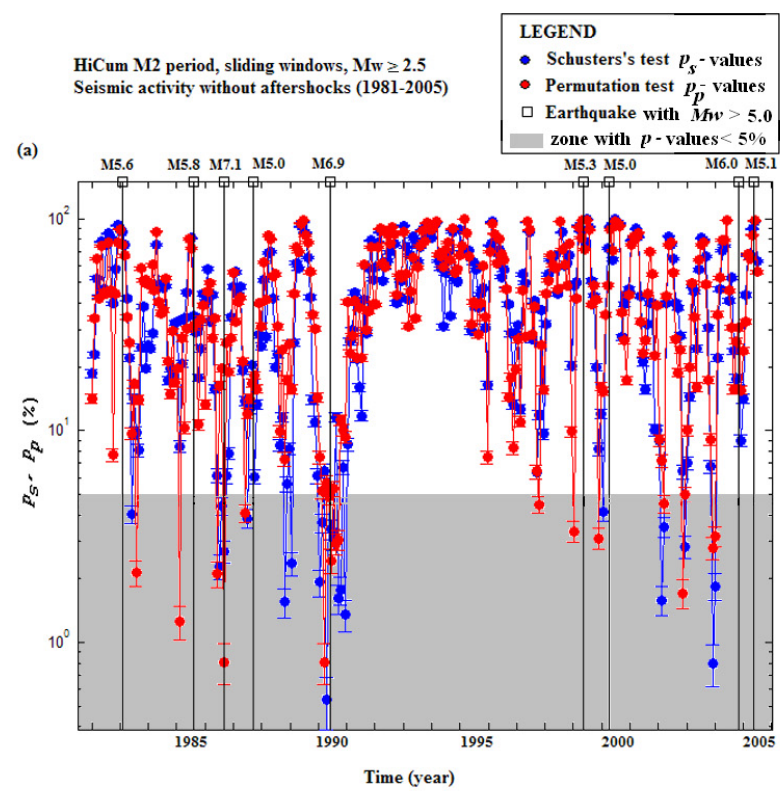

(b)

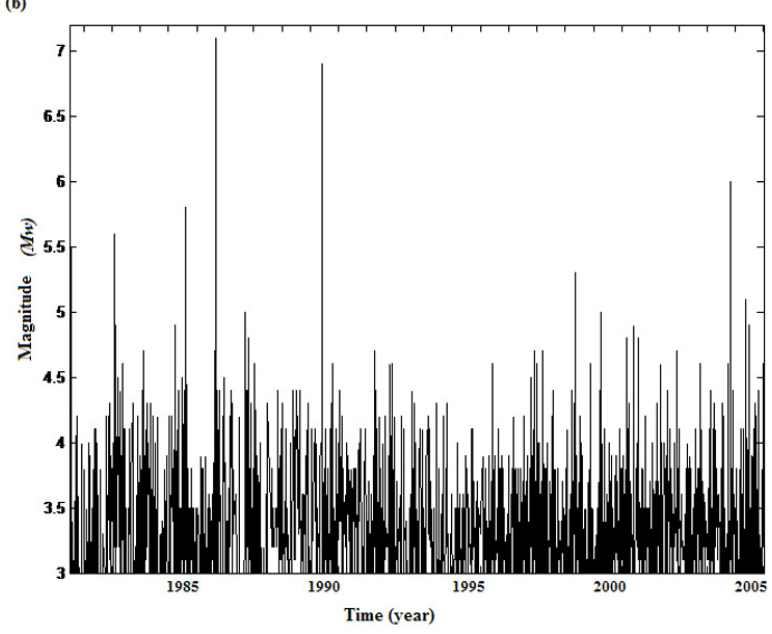

Fig. 9. (a) Temporal variation of the $p_{s}$-value (blue) and $p_{p^{-}}$ value (red) in every sliding window for HiCum with an $M 2$ period. The vertical bar represents the standard deviation of the $p_{s}$ and $p_{p}$-values. (b) Magnitude-time plot of the earthquake occurrences $(M w \geq 3.0)$. The aftershocks sequence was eliminated using the Kossobokov-Romashkova method.

1999). It is characterized by a prevailing intermediate depth seismicity which is in distinct confined volume (Bazacliu et al., 1999) (Fig. 4).

Important historical earthquakes happened on 10 November $1940(h=150 \mathrm{~km}, M w=7.7), 4$ March $1977(h=94 \mathrm{~km}$, $M w=7.4), 30$ August $1986(h=131 \mathrm{~km}, M w=7.1)$, and 30 May $1990(h=91 \mathrm{Km}, M w=6.9)$. These earthquakes reflect a predominantly compressive stress regime at this subcrustal range. The compressive tendency is becoming stronger with depth (Bala et al., 2003).

Earthquakes with $M w \geq 5.0$ from 1981 to 2005 are given

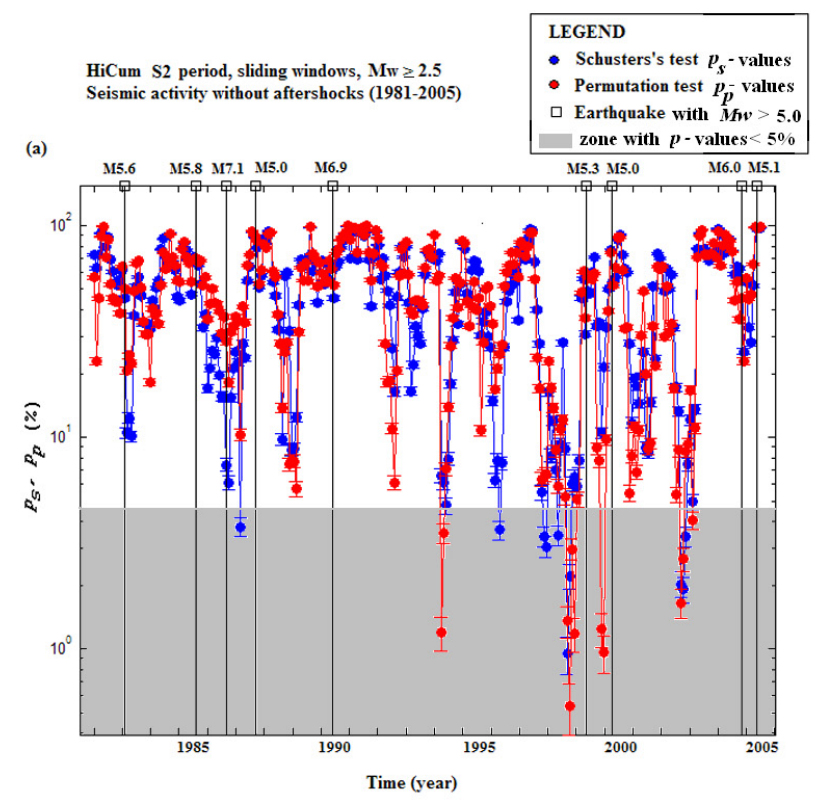

(b)

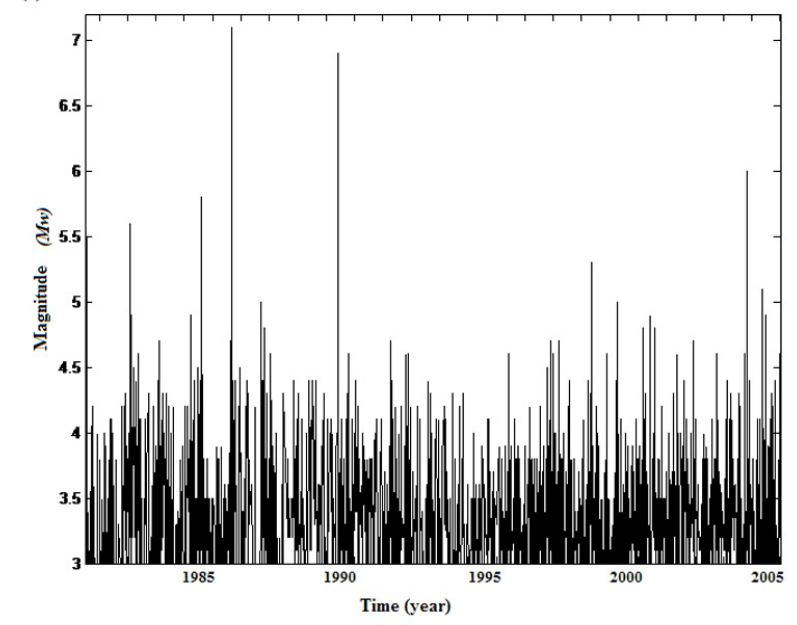

Fig. 10. (a) Temporal variation of the $p_{s}$-value (blue) and $p_{p}$-value (red) in every sliding window for HiCum with $\mathrm{S} 2$ period. The vertical bar represents the standard deviation of the $p_{s}$ and $p_{p}$-values. (b) Magnitude -time plot of the earthquake occurrences $(M w \geq 3.0)$. The aftershocks sequence was eliminated using the KossobokovRomashkova method.

in Table 2. The aftershocks sequence was eliminated by the Kossobokov-Romashkova method ${ }^{1}$ This method proposed a new way to characterize aftershocks according to a systematic analysis of the earthquakes. It defined all quakes, which occurred in the following $2 \mathrm{~d}$ as aftershocks after an earthquake with $M w$ from 2.5 to 5.0, $4 \mathrm{~d}$ for $M w$ from 5.0 to 5.5,

\footnotetext{
${ }^{1}$ Kossobokov, V. and Romashkova, L.: Re-establishing intermediate-term real-time prediction of strong earthquakes in the Vrancea region, CE-Project, Extreme Events: Causes and Consequences, Perugia 2-6 September, 2006.
} 
Table 2. Intermediate-depth earthquakes in the Vrancea zone with $M w \geq 5.0$ (1981-2005).

\begin{tabular}{cccccccccc}
\hline Year & Month & Day & Hour & Min & Sec & Lat.(deg) & Long. (deg) & Depth $(\mathrm{km})$ & Mag. $(M w)$ \\
\hline 1981 & 7 & 18 & 0 & 2 & 59 & 45.69 & 26.42 & 166.1 & 5.5 \\
1983 & 1 & 25 & 7 & 34 & 50 & 45.75 & 26.64 & 149.8 & 5.6 \\
1985 & 8 & 1 & 11 & 17 & 36 & 45.79 & 26.77 & 118.6 & 5.2 \\
1985 & 8 & 1 & 14 & 35 & 4 & 45.73 & 26.62 & 93.5 & 5.8 \\
1986 & 8 & 30 & 21 & 28 & 37 & 45.52 & 26.49 & 131.4 & 7.1 \\
1987 & 9 & 4 & 1 & 40 & 30 & 45.68 & 26.43 & 160.2 & 5.0 \\
1990 & 5 & 30 & 10 & 40 & 6 & 45.83 & 26.89 & 90.9 & 6.9 \\
1990 & 5 & 31 & 0 & 17 & 48 & 45.85 & 26.91 & 86.9 & 6.4 \\
1999 & 4 & 28 & 8 & 47 & 56 & 45.49 & 26.27 & 151.1 & 5.3 \\
2000 & 4 & 6 & 0 & 10 & 39 & 45.75 & 26.64 & 143.4 & 5.0 \\
2004 & 10 & 27 & 20 & 34 & 36 & 45.78 & 26.73 & 98.6 & 6.0 \\
2005 & 5 & 14 & 1 & 53 & 22 & 45.68 & 26.54 & 148.3 & 5.1 \\
\hline
\end{tabular}

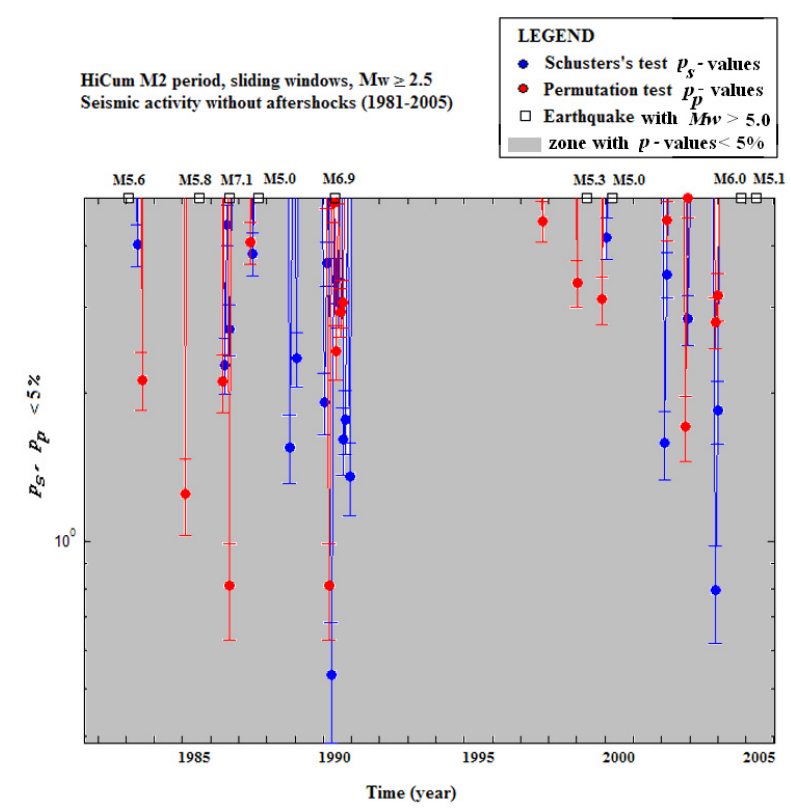

Fig. 11. HiCum $M 2$ period: sliding windows in which $p_{s}$ and $p_{p^{-}}$ values are $5 \%$ (18 values for $p_{p}$ coefficient and 20 values for $p_{S}$ coefficient).

8 days for $M w$ from 5.5 to $6.0,16 \mathrm{~d}$ for $M w$ from 6.0 to 6.5, $32 \mathrm{~d}$ for $M w$ from 6.5 to 7.0 and $64 \mathrm{~d}$ from 7.0 to 9.0.

After we analyzed the semidiurnal tidal effect on both cases with aftershocks $(N=2992)$ and without aftershocks (2242), we found some larger aftershocks series could induce bias peaks in the distribution. To avoid this, we decided to consider the cases without aftershocks.

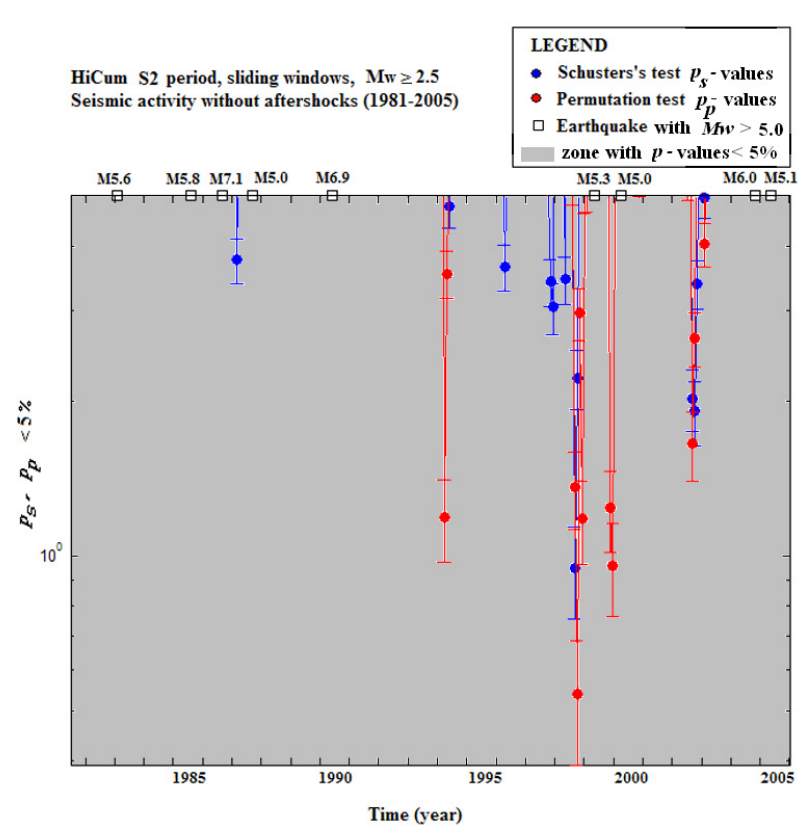

Fig. 12. HiCum $S 2$ period: sliding windows in which $p_{s}$ and $p_{p^{-}}$ values are $<5 \%$ (11 values for $p_{p}$ coefficient and 12 values for $p_{S}$ coefficient).

\section{Application and results}

We studied mainly the semidiurnal tidal components because the gravitational tidal forcing is a force, which could affect the dynamic processing at such depths. In the tidal potential, $M 2$ is the lunar principal wave with $12.42 \mathrm{~h}$ period and its amplitude is two times larger than the $S 2$ which is the solar principal wave having a $12 \mathrm{~h}$ period.

We computed the $M 2$ and $S 2$ tidal phase angle of each earthquake $(M w \geq 2.5$, focal depth $>60 \mathrm{~km})$ and attribute gravity values at the moment of earthquake occurrence which 
Table 3. Results of Schuster's and permutation tests applied on the all sets of earthquakes.

\begin{tabular}{lrlll}
\hline Wave & \multicolumn{2}{c}{ With aftershocks } & \multicolumn{2}{c}{ Without aftershocks } \\
\hline$M 2$ & $p_{s}=79.46 \%$ & $p_{p}=79.48 \%$ & $p_{s}=66.77 \%$ & $p_{p}=70.88 \%$ \\
$S 2$ & $p_{s}=0.86 \%$ & $p_{p}=3.54 \%$ & $p_{s}=15.78 \%$ & $p_{p}=10.22 \%$ \\
\hline
\end{tabular}

was calculated from a local model by Tsoft (Van Camp and Vauterin, 2005). We obtained the distribution of gravity values and earthquake numbers as a function of tidal phase angle. The dynamic patterns of tidal components were compared with the tendency of earthquake occurrence.

The same tendencies in the two cases are observed even if the aftershocks change the phase and the amplitude of the fitting curves (Figs. 5 and 6). This also changes the results of the two significance tests for a threshold at 5\% (Table 3). There is one exception ( $S 2$ wave with aftershocks not eliminated), the $p_{s}$ and $p_{p}$-values are much greater than 5\%. In these cases, the event distributions should be considered as random. It means that the processes induced by tidal triggering have a non repetitive long term pattern. In order to evaluate the possible correlations between earthquake occurrence and the semidiurnal tidal wave in a shorter time interval, a sliding window algorithm was developed. We calculate the distribution of all events in the $M 2$ and $S 2$ cycles for a series of sliding windows with one year length where the sliding step is $30 \mathrm{~d}$. There are 287 set distributions (Figs. 7 and 8) covering the entire sets of data (1981 to 2005).

Each distribution was evaluated by Shuster's and Permutation tests. Figure 9 and Fig. 10 show that the $p_{s}$ and $p_{p}$ value for the two test results are very similar. The hypothesis becomes more convincing because the same conclusion is confirmed by two independent statistical methods.

When the $p_{s}$ and $p_{p}$ values are plotted in real time, a spatial pattern could be found both at the $M 2$ and $S 2$ cycle (Figs. 11 and 12), but obvious in $M 2$ cycle (Fig. 11). The $p_{s}$ and $p_{p}$ values are decreasing until a large earthquake occurs. After that, the values go up, and then decrease before another large event happens. Similar phenomena were also reported in the study of the Tokai region earthquakes (Tanaka et al., 2006).

Future studies should focus on $p$ value criteria, on the relation between spatial and magnitude patterns and the quake occurrence. It could be useful for detecting potential precursors for earthquake forecasting.

\section{Conclusions}

We analyzed the correlation between the main semidiurnal tidal waves and the earthquake occurrence. Two different statistical tests were applied on the $M 2$ and $S 2$ tidal phase angles' distribution calculated from each event. The conclusion regarding robustness of the tidal triggering effect obtained with Schuster's test is strengthened by the Permutation complementary test.

When we test the distribution determined from all phase angles of earthquakes, no correlation has been found by either tests. However, when we selected a series of one year length sliding window with a 30 days moving step, there is significant correlation between the tidal potential and earthquake occurrence for some windows.

A systematic temporal pattern related to the decrease of the $p$-values precedes the occurrence of larger earthquakes in the Vrancea seismic region. This pattern could be considered as a kind of precursor. The possible physical consequences of the tidal effect could constrain the research on the seismic source characteristics and their dynamical patterns.

We could imagine that for seismic zones, tidal modulation of fluid pressure is acting before the rupture process.

Acknowledgements. We thank M. Radulian and M. Popa, the National Institute for Earth Physics for providing the ROMPLUS catalogue. We are very grateful P. Hodor for the very useful discussions on the permutation test and on the software implementation. We would like to thank to the bilateral cooperation between Royal Observatory of Belgium and the Institute of Geodynamics of the Romania Academy for allowing us to optimize the conditions in which we could finalize our work. Thanks a lot to all the colleagues for their kind support to our project. We are grateful for the anonymous reviewers for helpful comments, and English improvement by T. van Dam. Thanks M. Everaerts for his contributions.

Edited by: : M. Contadakis

Reviewed by: two anonymous referees

\section{References}

Ardeleanu, L.: Statistical Models of the Seismicity of the Vrancea Region, Romania, Natural Hazards, 19, 151-164, 1999.

Bala, A., Radulian, M., and Popescu, E.: Earthquakes distribution and their focal mechanism in correlation with the active tectonic zones of Romania, J. Geodyn., 36, 129-145, 2003.

Bazacliu, O. and Radulian, M.: Seismicity Variations in Depth and Time in the Vrancea (Romania) Subcrustal Region, Natural Hazards, 19, 165-177, 1999.

Cadicheanu, N., van Ruymbeke, M., Zugravescu, D., Everaerts, M. and Howard, R.: Periodical tendencies in Vrancea seismic activity detected by the Hi-Cum stacking method, Rev. Roum. Geophysique, 50, 31-57, 2006.

Curchin, J. M. and Pennington, W. D.: Tidal triggering of intermediate and deep focus earthquakes, J. Geophys. Res. 92, $13957-$ $13967,1987$.

Enescu, D. and Enescu, B. D.: Possible cause - effect relationships between Vrancea (Romania) earthquakes and some global geophysical phenomena, Natural Hazards, Kluwwer Academic Publishers, 19, 233-245, 1999.

Fisher, R. A.: The Design of Experiment, New York: Hafner, 1935.

Heaton, T. H.: Tidal triggering of earthquakes, Geophys. J. R. Astron. Soc., 43, 307-326, 1975. 
Heaton, T. H.: Tidal triggering of earthquakes, Bull. Seismol.Soc. Am., 72, 2181-2200, 1982.

Knapp, H. J., Knapp, C., Raileanu, V., Matenco, L., Mocanu, V. and Dinu, C.: Crustal constraints on the origin of mantle seismicity in the Vrancea Zone, Romania: The case for active continental lithospheric delamination, Tectonophysics, 410, 311-323, 2005.

Knopoff, L.: Earth tides as a triggering mechanism for earthquakes, Bull. Seismol. Soc. Am., 54, 1865-1870, 1964.

Melchior, P.: The Tides of the Planet Earth, Pergamon Press, New York, 1978.

Oncescu, M. C., Marza, V. I., Rizescu, M., and Popa, M.: The Romanian Earthquake Catalogue between 984-1999, in Vrancea Earthquakes: Tectonics, Hazard and Risk Mitigation, edited by: Wenzel, F. and Lungu, D., and Novak, O., 43-47, Kluwer Academic Publishers, Dordrecht, Netherlands, 1999 (Catalogue under continuous update).

Fisher, R. A.: The Design of Experiment, New York: Hafner, 1935.

Pitman, E. J. G.: Significance tests which may be applied to samples from any population, Part III: The analysis of variance test, Biometrika, 29, 322-335, 1938.

Rydelek, P. A., Sacks, I. S., and Scarpa, R.: On tidal triggering of earthquakes at Campi Flegrei, Italy. Geophys. J. Int., 109, 125137, 1992.

Shudde, R. H. and Barr, D. R.: An analysis of earthquake frequency data, Bull. Seismol. Soc. Am., 67, 1379-1386, 1977.

Schuster, A.: On lunar and solar periodicities of earthquakes, Proc. R. Soc. Lond., 61, 455-465, 1897.

Simpson, J. F.: Earth tides as a triggering mechanism for earthquakes, Earth Planet. Sci. Lett., 2, 473-478, 1967.

Stavinschi, M. and Souchay, J.: Some correlations between Earthquakes and Earth Tides, Acta Geod. Geoph. Hung., 38(1), 77-92, 2003.

Stroup, D. F.: Pulse of the seafloor: Tidal triggering of microearthquakes at $9^{\circ} 50^{\prime} \mathrm{N}$ East Pacific Rise, Geophys. Res. Lett., 34(15), 2007.

Tanaka, S., Ohtake, M., and Sato, H.: Evidence for tidal triggering of earthquakes as revealed from statistical analysis of global data, J. Geophys. Res., 107(5B10), 2211, doi: 10.1029/2001JB001577, 2002.
Tanaka, S., Sato, H., Matsumura, S., and Ohtake, M.: Tidal triggering of earthquakes in the subducting Philippine Sea plate beneath the locked zone of the plate interface in the Tokai region, Japan, Tectonophysics, 417, 69-80, 2006.

Tolstoy, M., Vernon, F. L., Orcutt, J. A., and Wyatt, F. K.: Breathing of the seafloor: tidal correlations of seismicity at Axial volcano,Geology, 30, 503-506, 2002.

Tsuruoka, H., Ohtake, M., and Sato, H.: Statistical test of the tidal triggering of earthquakes: contribution of the ocean tide loading effect, Geophys. J. Int., 122, 183-194, 1995.

van Camp, M. and Vauterin, P.: Tsoft: graphical and interactive software for the analysis of time series and Earth tides, Computers in Geosciences, 31(5) 631-640, 2005.

van Ruymbeke, M., Zhu, P., Cadicheanu, N., and Naslin, S.: Very Weak Signals (VWS) detected by stacking method according to different astronomical periodicities (HiCum), Nat. Hazards Earth Syst. Sci., 7, 651-656, 2007, http://www.nat-hazards-earth-syst-sci.net/7/651/2007/.

van Ruymbeke, M., Howard, R., Pütz, P., Beauducel, F., Somerhausen, A. and Barriot, J-P.: An Introduction to the use of HICUM for signal analysis, BIM 138, 10 955-10 966, 2003.

Vidale, J. E., Agnew, D. C., Johnston, M. J. S., Oppenheimer, D. H.: Absence of earthquake correlation with earth tides: an indication of high preseismic fault stress rate, J. Geophys. Res., 103, 24 567-24 572, 1998.

Zugravescu, D., Enescu, D., Delion, D., Fatulescu, I., and Dorobantu, R.: Some correlations between the mechanism of Vrancea earthquakes occurrence and Earth tides, Rev. Roum. Geophys., 29, 1-34, 1985.

Zugravescu, D., Fatulescu, I., Enescu, D., Danchiv, D., and Haradja, O.: Peculiarities of the correlation between gravity and earthquakes, Rev. Roum. Geophys., 33, 3-10, 1989.

Wilcock, W. S. D.: Tidal triggering of microearthquakes on the Juan de Fuca Ridge, Geophys. Res. Lett., 28, 3999-4002, 2001. 